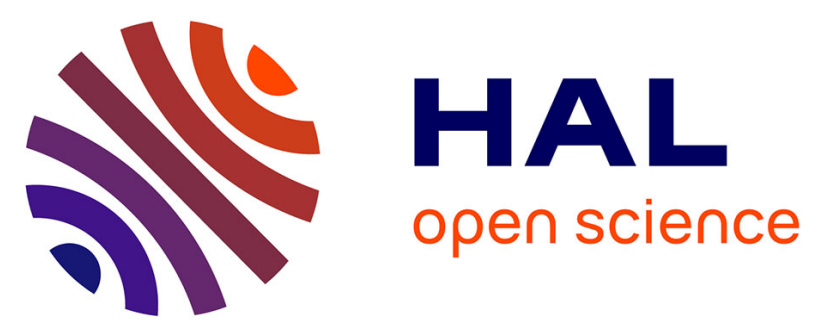

\title{
XFEM and CZM modeling to predict the repair damage by composite patch of aircraft structures: Debonding parameters
}

\author{
Mohammed Amine Bellali, Boualem Serier, Mohamed Mokhtari, Raul D.S.G. \\ Campilho, Frédéric Lebon, Hamida Fekirini
}

\section{To cite this version:}

Mohammed Amine Bellali, Boualem Serier, Mohamed Mokhtari, Raul D.S.G. Campilho, Frédéric Lebon, et al.. XFEM and CZM modeling to predict the repair damage by composite patch of aircraft structures: Debonding parameters. Composite Structures, 2021, 266, pp.113805.

10.1016/j.compstruct.2021.113805 . hal-03354116

\author{
HAL Id: hal-03354116 \\ https://hal.science/hal-03354116
}

Submitted on 26 Oct 2021

HAL is a multi-disciplinary open access archive for the deposit and dissemination of scientific research documents, whether they are published or not. The documents may come from teaching and research institutions in France or abroad, or from public or private research centers.
L'archive ouverte pluridisciplinaire HAL, est destinée au dépôt et à la diffusion de documents scientifiques de niveau recherche, publiés ou non, émanant des établissements d'enseignement et de recherche français ou étrangers, des laboratoires publics ou privés. 


\title{
XFEM and CZM modeling to predict the repair damage by composite patch of aircraft structures: Debonding parameters
}

\author{
Mohammed Amine Bellali ${ }^{\mathrm{a}, *}$, Boualem Serier ${ }^{\mathrm{a}}$, Mohamed Mokhtari ${ }^{\mathrm{b}}$, Raul D.S.G. Campilho ${ }^{\mathrm{c}}$, Frederic Lebon ${ }^{\mathrm{d}}$, \\ Hamida Fekirini ${ }^{\text {a }}$ \\ ${ }^{a}$ Laboratory of Physical Mechanics of Materials (LMPM), DjillaliLiabes University of Sidi Bel-Abbes, Algeria \\ ${ }^{\mathrm{b}}$ LaRTFM Laboratory, National Polytechnic School of Oran M.A. (ENPO), Oran, Algeria \\ ${ }^{\mathrm{c}}$ Department of Mechanical Engineering, Instituto Superior de Engenharia do Porto, Instituto Politécnico do Porto, Porto, Portugal \\ ${ }^{\mathrm{d}}$ Laboratory of Mechanics and Acoustics, Aix-Marseille University, CNRS, Centrale Marseille, Marseille, France
}

In this work, a model based on the combination of two approaches XFEM and CZM, has been used to predict the damage of repairs by composite patch (patch/adhesive/plate assembly). This degradation is analyzed in terms of adhesive damage considering both initiation and propagation of interfacial debonding. The interfacial cohesive zone of the patch/adhesive/plate system is defined by its cohesive properties and its resistance to debonding estimated from the displacement-load curves.

This study highlights, as a function of the adhesive properties of the plate/patch interface, the competition between two degradation mechanisms: adhesive damage (through a mechanism of initiation and propagation of patch debonding from the plate) and plate damage (through a phenomenon of crack initiation and propagation emanating from notch). It also highlights, depending on the nature of the interface, four physical parameters: the bending deflection of the repaired plate, the displacement path of the patch-reinforced plate, the debonding resistance and the interfacial shear stresses, characteristic of the adhesive joint damage and their interactions with the interface. This is the originality of this study. Results show that XFEM simulations based on the CZM model allow adequate prediction of the damage of the patch/adhesive/plate assemblies.

\section{Introduction}

In view of their many advantages, in particular high stiffness, low density, excellent strength properties, good corrosion resistance etc., polymer matrix composites are used in the industrial sector as repair and reinforcement materials for damaged structures and working under increasingly complex and severe stress conditions. This technique consists in bonding a composite patch to the damaged part of the structure.

Composite bonded repair can therefore offer significantly improved mechanical performance of aircraft structures in terms of stiffness, static strength and fatigue resistance [1-5]. The effectiveness of the repair depends, among other things, on the mechanical and geometrical properties of the adhesive joint [6-9]. Due to its low stiffness, the adhesive is therefore the weakest component of the plate/adhesive/composite patch systems. Indeed, $53 \%$ of the failures observed in air- craft structures repaired by composite patches are due to the degradation of the adhesive [10]. Patch debonding is practically the main cause of repair failure. Few research works have been devoted to the analysis of this physical phenomenon in the case of patch repair. Thus, Denney [11] has analyzed the effect of debonding on the strength and longevity of the repair through fatigue tests. This author shows that the service life of the repaired structure falls as the size of the debonding increases. According to Deheeger [12] the shear stresses induced in the adhesive joint are responsible for the debonding. In another study [13-16], by studying different debonding configurations, it was shown that debonding increases over a large central width and leads to the edge of the repair patch becoming disbonded.

Zarrinzadeh et al [17] analyzed the debonding of the adhesive layer bonding the cracked area of a pipeline to the composite patch. They show that modeling, using both XFEM and CZM (cohesive zone model) methods, can predict a more realistic behavior of the structure

\footnotetext{
* Corresponding author.

E-mail addresses: medaminebellali@gmail.com (M.A. Bellali), serielem@yahoo.fr (B. Serier), Mokhtarimohamed44@yahoo.com (M. Mokhtari), raulcampilho@gmail.com (R.D.S.G. Campilho), frederic.lebon@univ-amu.fr (F. Lebon), fekirini.hamida@gmail.com (H. Fekirini).
} 
compared to similar experimental tests with the objective of improving the performance of these structures in terms of increased fatigue life. Sahli et al [18] analyzed numerically and experimentally by acoustic emission the debonding process in the case of patch repair of aircraft structures. They show that adhesive damage starts at the free edges of the structure and in the area around the notch. Ban et al [19], proposed a damage area ratio for the prediction of adhesive joint strength. For repairs using Structural Epoxy Adhesive FM 73, the corresponding damage ratio for this adhesive is approximately 0.247. In another study, Magalhães et al [20] showed that failure of the adhesive layer does not occur by crack growth, but by the initiation and propagation of an area damaged by microcracking or microcavitation. These authors conclude that the damage propagates within the adhesive near the adhesive interface. The observation of a thin adhesive layer on the adhered surface showed that the fracture, which appeared to be adhesive, is in fact cohesive.

Bouanani et al [21] in the case of repair of aircraft structures using the modified damaged area theory showed that the damage caused by the adhesive is mainly located on the free edges of the structure and in the area around the crack. Theoretically, the damage zone is defined as an area in which the stress exceeds the ultimate stress by $7.87 \%$. Nour et al [22], using modified damage zone models, analyzed the effect of adhesive and plate thickness on the fracture behavior of FM 73 adhesive used for composite patch repair of aircraft structures. They show that as adhesive thickness increases, the damaged area of the adhesive joint increases and conversely, as the thickness of the structure is thin, adhesive damage becomes more severe. Bellali et al [23], using the CZM cohesive zone approach and the extended finite element method, analyzed, in terms of debonding resistance, the damage of composite patch repair of aircraft structures. They show that this resistance is closely related to the stacking sequences of the patch and the size of the repaired defect.

The Cohesive Zone Model (CZM), according to Khoramishad et al. [24], has advantages such as the consideration of stresses and finite stresses at the edge of the adhesive. Da Silva and Campilho [25], have shown that the Cohesive Zone Model (CZM) remains a reliable technique for studying adhesive damage in adhesively bonded structures.

The cohesive CZM model has rarely been used for the analysis of interfacial degradation of structures repaired by bonded composite patch. The present study fits into this context and aims at predicting the degradation of the bonded composite patch repair of aircraft plates made of notched Al 2024 T3. This degradation is analyzed in terms of interfacedamage (adhesive) of a plate/interface/patch assembly. For this purpose, a combination of the Extended Finite Element Method (XFEM) and the Cohesive Zone Model (CZM) was used for the 3D modelling of the mechanical behavior of this assembly subjected to tensile stresses (as imposed displacements).

The analysis highlighted, according to the nature of the interface, the preferred sites of debonding and the mechanisms of the patch debonding and allowed the development of the physical parameters of the adhesive layer damage: the bending deflection of the repaired plate, the displacement trajectory of the notched plate, the resistance to debonding and the interfacial shear stresses.

This work provides, on the one hand, the interaction between these parameters and patch debonding, and on the other hand, the competition between two physical phenomena: damage to the adhesive layer (debonding) and the propagation of cracks emanating from notches in the repaired plate. This study is practically to our knowledge are of the first in this field of repair. The prediction of patch/interface/plate system repair degradation due to interfacial bond failure has been very little studied.

\section{Extended finite element method XFEM}

In general, the enhancement functions group together asymptotic functions close to the characteristic tip of the crack tip singularity and a discontinuous function that represents the jump in displacement across the surfaces of the crack. Thus, the XFEM technique enriches a finite element approximation based on the standard displacement with discontinuous functions.

The approximation of a vectorial displacement function $\mathrm{u}$ to the partition of the unit enrichment (Fig. 1) in the XFEM is of the form $[26,27]$ :

$$
\begin{aligned}
& u_{x f e m}(x)=\sum_{i \in I} u_{i} N_{i}(x)+\underbrace{\sum_{j \in I} b_{j} N_{j}(x) H(x)}_{\text {Only Heaviside nodes }}+ \\
& \underbrace{\sum_{k \in K_{1}} N_{k}(x)\left(\sum_{l=1}^{4} c_{k}^{l 1} F_{l 1}(x)\right)+\sum_{l=1} N_{k}(x)\left(\sum_{k}^{4} c_{k}^{l 2} F_{l 2}(x)\right)}_{\text {Only crack-tip nodes }}
\end{aligned}
$$

where $x=\{x, y\}$ designates the two-dimensional coordinate system, $I$ correspond to the set of all the nodes of the mesh, $N_{i}(x)$ represents the shape function associated with nodei, $u_{i}$ are the degrees of freedom of node $i, H(x)$ is the Heaviside function or the jump function. $N_{j}$ are the shape functions related to the discontinuity of node $j . J \subset I$ Is the set of nodes whose support of the shape function is cut by a crack, $b_{j}$ is the vector of the corresponding additional degrees of freedom for the modeling of the surfaces (lips) of the crack (and not of the crack fronts). In the case where the crack is aligned with the mesh, $b_{j}$ corresponds to the crack opening. The parameters $K_{1} \subset I$ and $K_{2} \subset I$ represent the set of nodes whose shape function support contains the first and second crack tips in their domain of influence, respectively. $c_{k}^{l 1}$ and $c_{k}^{l 2}$ designate the vector of corresponding additional degrees of freedom that are related to the modeling of crack fronts, since the areas in the area near these fronts are enriched with four different crack functions. The parameters $F_{l 1}(x)$ and $F_{l 2}(x)$ designate the cracking front enrichment functions.

The first term of equation (1) applies to all nodes, while the second term is valid for nodes whose support of the shape function is cut by the inside of the crack, the third and fourth term is only used for nodes whose support of the shape function is cut by the tip of the crack.

In the absence of enrichment, expression (1) is reduced to the classical finite element approximation. Throughout the problem domain, nodes that are not enriched by a Heaviside function or an asymptotic crack tip function are associated with conventional
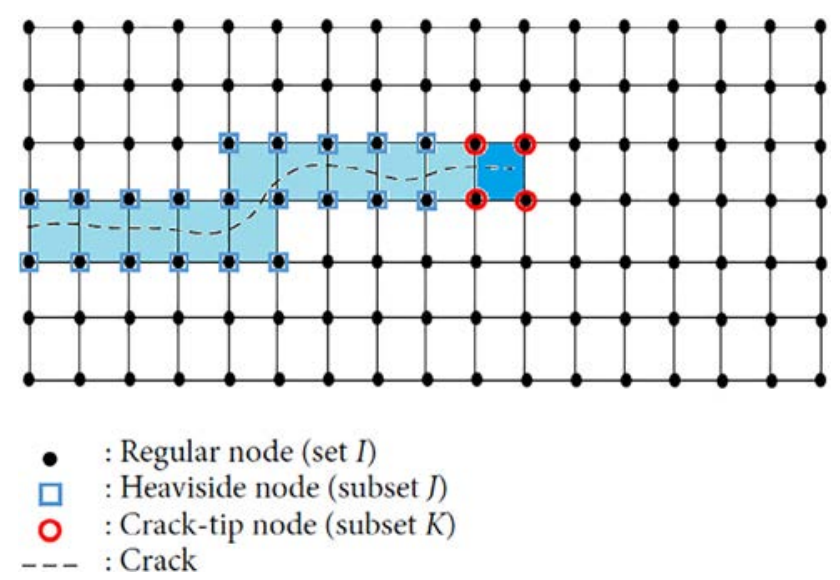

Fig. 1. Enriched nodes in the XFEM approach [28]. 
FEM shape functions. Therefore, (1) can be simplified to include only the first summation term leading to the traditional MEF formulation that reads as

$u_{f e m}(x)=\sum_{i} u_{i} N_{i}(x)$

\section{Enrichment functions}

To model the discontinuity of the displacement field, the enrichment function $H(x)$ is expressed by:

$H(x)=\left\{\begin{array}{lr}1 & \text { if }\left(x-x^{*}\right) \cdot n \geq 0 \\ -1 & \text { otherwise }\end{array}\right.$

where $x$ corresponds to a Gauss point, $x^{*}$ located on the crack, is the closest point to $x$ (Fig. 2), and $\mathrm{n}$ is the outer normal unit to the crack at $x^{*}$.

Fig. 2 shows the discontinuous jump function across the surface of the crack. In order to model the crack fronts and improve the representation of the fields relative to these fronts, crack tip enhancement functions are used in the element containing this tip. For an isotropic material, the enrichment functions of the crack front $F_{l}(r, \theta)$, shown in Fig. 2, are expressed as:

$\left\{F_{l}(r, \theta)\right\}_{l=1}^{4}=\left[\sqrt{r} \sin \frac{\theta}{2}, \sqrt{r} \cos \frac{\theta}{2}, \sqrt{r} \sin \theta \sin \frac{\theta}{2}, \sqrt{r} \sin \theta \cos \frac{\theta}{2}\right]$

In this expression (4) $(r, \theta)$ refers to the local polar coordinate system whose origin is located at the tip of the crack, the tangent $s$ is at $\theta=0$, and the outside normal at $\theta=90^{\circ}$ is denoted by $n$ (Fig. 2). Equation (4) is composed of four terms, the first $\sqrt{r} \sin \left(\frac{\theta}{2}\right)$, is a discontinuous function in the plane of the crack while the last three are continuous. It should be noted, however, that the discontinuity at the crack front can be characterized by other sets of functions, or even by a single discontinuous function over the entire geometry of the crack tip. Multiple cracks can be treated in the above framework, incorporating additional enrichment of the discontinuity and almost the entire tip.

\section{The cohesive zone modeling (CZM) approach}

When the cohesive surfaces separate, the traction first increases until a maximum is reached and then reduces to zero, resulting in complete separation. The change in traction versus displacement is shown on a curve and is called the traction-displacement curve (Fig. 3). The area under this curve corresponds to the energy required for separation. The cohesive zone approach (CZM) mathematically maintains conditions of continuity, despite the physical separation. It eliminates the singularity of the stress and the limit to the cohesive strength of the material.

The (CZM) approach remains currently the most suitable model for the description of adhesive damage. In this approach, the damage path is located entirely in the cohesive zone (Fig. 3). The damage evolution model is a linear traction-traction separation law (Fig. 3), defined by a node surface in a mesh where no interaction has been introduced between the surfaces. The cohesive law is an initial regime of undamaged elastic behavior where the surfaces are jointly bound together.

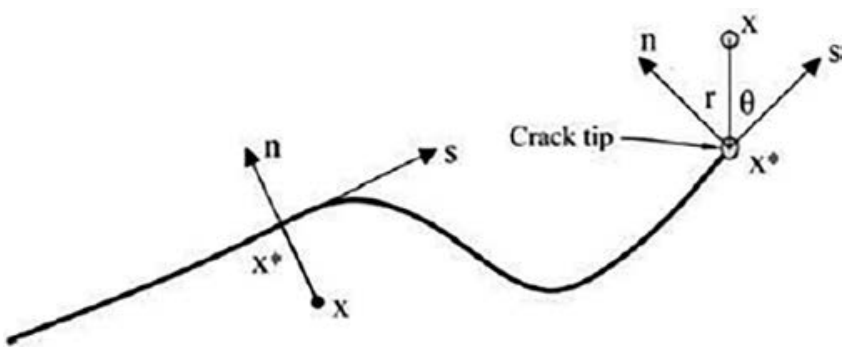

Fig. 2. Representation of normal and tangential coordinates for a crack [26].

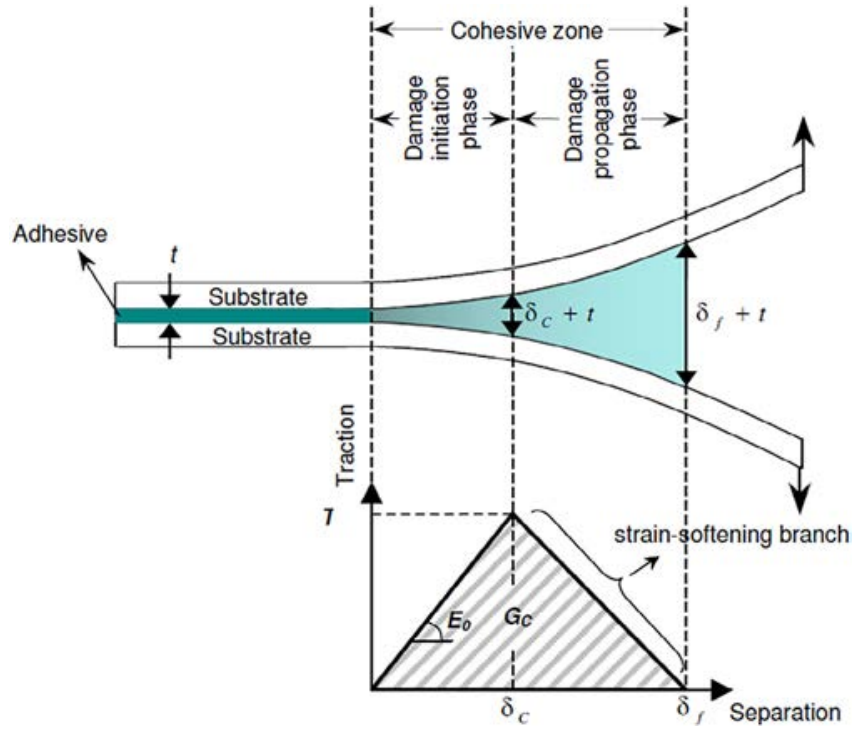

Fig. 3. Schematic damage process zone and corresponding bi-linear traction-separation law in an adhesively bonded joint [29].

A damage initiation threshold stress is defined, thus initiating a softening behavior in which stiffness degradation increases as the surfaces move away from each other (Fig. 1). For this purpose, the two surfaces reach a level of separation such that the stiffness that connects them tends towards zero and they are completely "detached" from each other.

The initiation criterion for the adopted tensile-separation law is the quadratic nominal stress (QUADS) [26]. The latter takes into account the competing quadratic relationships between the nominal stress and the allowable stress acting in different directions (Fig. 4).

$\left(\frac{T_{I}}{T_{I, c}}\right)^{2}+\left(\frac{T_{I I}}{T_{I I, c}}\right)^{2}+\left(\frac{T_{I I I}}{T_{I I I, c}}\right)^{2}=1$

where $T_{I, c}$ is the nominal stress in the pure normal mode, $T_{I, c}$ is the nominal stress in the first shear direction and $T_{I I I, c}$ is the nominal stress in the second shear direction.

The law of propagation of damage adopted in this work corresponds to the Benzeggagh-Kenane (BK) [31] criterion of rupture. This approach is particularly useful when the critical fracture energies during pure deformation in the first and second shear directions are the same, i.e., for isotropic fractures or $G_{I I C}=G_{I I I C}$. It is given by:

$G_{I C}+\left(G_{I I C}+G_{I C}\right)\left\{\frac{G_{S}}{G_{T}}\right\}^{\eta}=G_{c}$

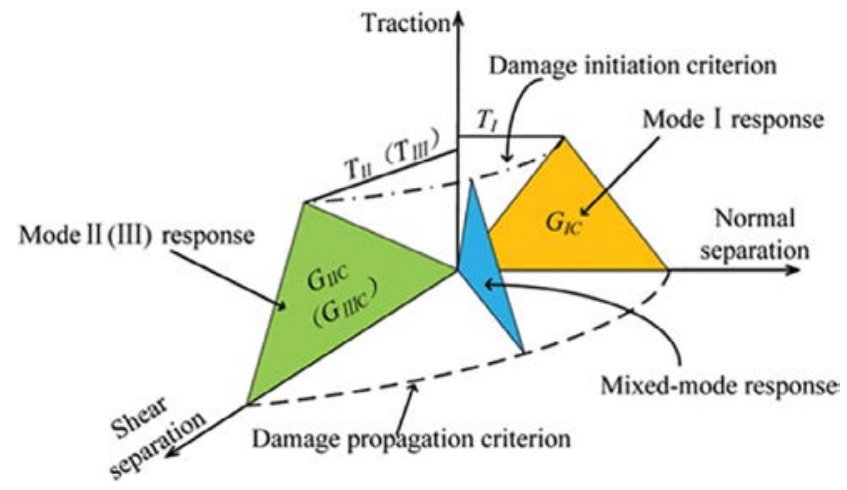

Fig. 4. Mixed-mode triangle traction-separation law [30]. 
where $G_{S}=G_{I I}+G_{I I I}, G_{T}=G_{I}+G_{S}$ and $\eta$ a characteristic material parameter, $G_{i c}$ is the critical energy release rate associated with fracture mode $\mathrm{i}$. (with $\mathrm{i}=\mathrm{I}$ Mode I, $\mathrm{i}=\mathrm{II}$ and $\mathrm{i}=$ III modes II and III respectively).

\section{Finite element modeling}

The analysis of patch/adhesive/plate assembly damage in terms of interfacial damage requires the development of three-dimensional geometric and numerical models.

The geometrical model is composed of a 2024-T3 aluminum alloy plate, used in aircraft structures, of the following size: height, $\mathrm{H}=140 \mathrm{~mm}$, width, $\mathrm{w}=50 \mathrm{~mm}$, thickness, $\mathrm{e}=2 \mathrm{~mm}$. This plate, containing a central circular notch with a radius of $5 \mathrm{~mm}$, is subjected longitudinally to an imposed displacement "U" (Fig. 5). The latter is imposed on the same plate whose area weakened by the notch effect is repaired using a composite patch, square in shape, with the following dimensions: height, $\mathrm{H}=50 \mathrm{~mm}$, width, $\mathrm{w}_{\mathrm{r}}=50 \mathrm{~mm}$, thickness, $\mathrm{e}_{\mathrm{r}}=2 \mathrm{~mm}$, bonded with an adhesive (Fig. 5).

Cohesive elements were used to model the damage of the adhesive layer (debonding of the patch). The extended finite element method (XFEM) was used for the analysis of the mechanical fracture behavior

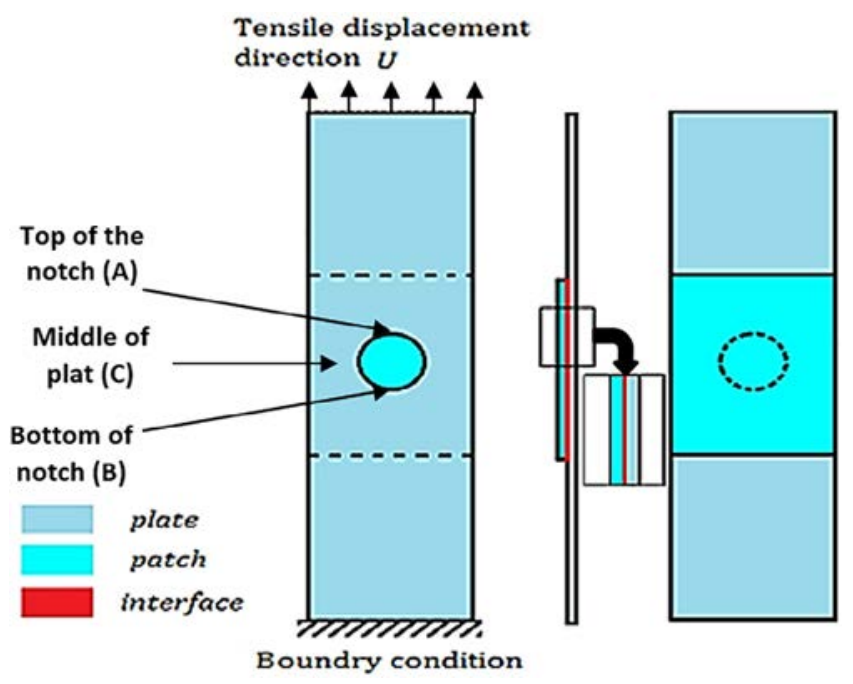

Fig. 5. Analyzed geometric model and boundary conditions. (crack initiation and propagation) of the repaired and non-repaired patch.

In this study, the criteria for initiation and propagation of debonding are illustrated by relationships (5) and (6) respectively.

The XFEM technique requires the adoption of a plate damage criterion of the plate/adhesive/patch system, based on maximum principal stress (MAXPS) [26]

$\left\{\frac{\left\langle\sigma_{\max }\right\rangle}{\sigma_{\max }^{0}}\right\}=1$

$\sigma_{\max }$ and $\sigma_{\max }^{0}$ are the given principal stress and the maximum principal stress. This criterion evaluates the stress ratios between a given stress value and the maximum nominal stress. XFEM modeling requires the adoption of this priming criterion.

The numerical model (Fig. 6) was partitioned by an interface where the three plate/adhesive/patch components share the same nodes, so that the same mesh architecture is maintained for each model studied. The cohesive element was chosen as the interface between the plate and the patch with a practically geometrically negligible thickness. The notched plate and the patch are joined together with an adhesive layer that has a negligible thickness (Fig. 6). Failure of the interface directly leads to patch-plate separation. The plate/adhesive/patch system is assumed to be perfectly bonded.

The prediction of repair degradation, in terms of interface damage, is analyzed according to the nature of the adhesive. Fig. 6 shows the mesh used for the three elements of the structure: plate/ adhesive/patch.

Abaqus ${ }^{\circledR}$ software, based on finite elements, was used to simulate the mechanical behavior of plate/adhesive/patch assemblies under tensile stress. This modeling uses 13,428 C3D8R solid elements for the plate notched with the same type of 5554 elements for the patch. The adhesive (interface) was modeled with typical COH3D8 elements of 2214 elements.

Patch-plate decohesion was modeled by maintaining the same nodes on the two adjacent faces of the repaired area. For a reliable analysis of repair degradation in terms of debonding, it is necessary to have an appropriate number of mesh elements in the adhesion area.

It should be noted, however, that the elements of the cohesive zone COH3D8 do not represent any physical material, but have the particularity of generating nodal forces based on interpolated separation displacements and the tractions generated by these displacements. In other words, these elements characterize the interfacial bonding forces (cohesive forces) generated when interface elements are pulled from opposite sides. The cohesive elements, jointly linked to the two upper

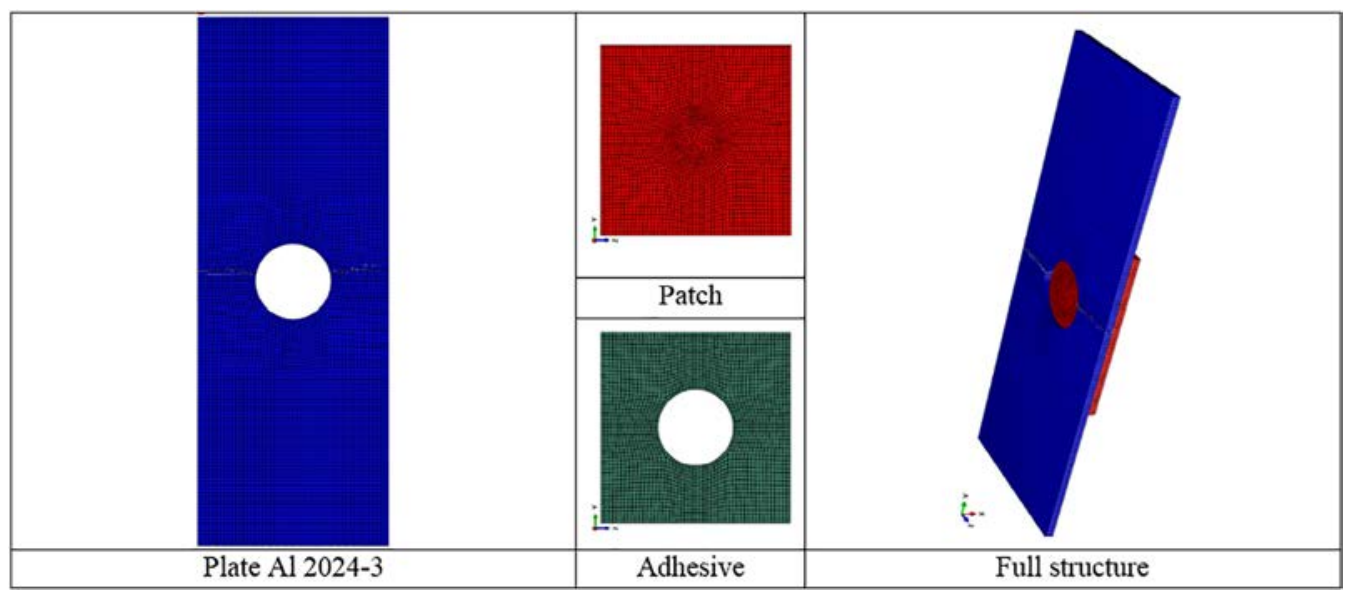

Fig. 6. Mesh of the analyzed assembly using Abaqus ${ }^{\circledR}$ software. 
and lower contact parts of the interface, share the same nodes or by an interfacial link.

\section{Assembly materials}

The mechanical properties of the studied assembly, consisting of an Al 2024-T3 plate repaired using a carbon/epoxy type laminated composite patch bonded to the notched part of the plate, are grouped in Tables 1 and 2. The mechanical tensile behavior (stress-strain curve) of the plate is shown in Fig. 7.

The modelling of the mechanical fracture behavior of the patch/adhesive/plate connections was carried out by taking into account the real elastoplastic nature of the plate (Fig. 7), which is weakened by the presence of a notch.

The non-linear part of this curve characterizing the plasticity of the plate and the last two points of the plastic stress-strain curve have been taken into account in the modelling of the failure once the ulti-

Table 1

Mechanical properties of the $\mathrm{Al}$ 2024-T3 plate.

\begin{tabular}{ll}
\hline Yield stress $(\mathrm{R} 0.2)=230 \mathrm{MPa}$, & Maximum stress $(\mathrm{Rm})=452 \mathrm{MPa}$ \\
Percentage elongation $(\mathrm{A})=2.4 \%$ & $\mathrm{E}=68.8 \mathrm{GPa} \gamma=0.33$ \\
\hline
\end{tabular}

Table 2

Mechanical properties of composites [33].

\begin{tabular}{lll}
\hline $\mathrm{E}_{1}=1.53 \mathrm{E}+05 \mathrm{MPa}$ & $\nu_{12}=2.58 \mathrm{E}-01$ & $\mathrm{G}_{12}=4.57 \mathrm{E}+03 \mathrm{MPa}$ \\
$\mathrm{E}_{2}=9.10 \mathrm{E}+03 \mathrm{MPa}$ & $\nu_{13}=2.58 \mathrm{E}-01$ & $\mathrm{G}_{13}=4.57 \mathrm{E}+03 \mathrm{MPa}$ \\
$\mathrm{E}_{3}=9.10 \mathrm{E}+03 \mathrm{MPa}$ & $\nu_{23}=3.84 \mathrm{E}-01$ & $\mathrm{G}_{23}=3.15 \mathrm{E}+03 \mathrm{MPa}$
\end{tabular}

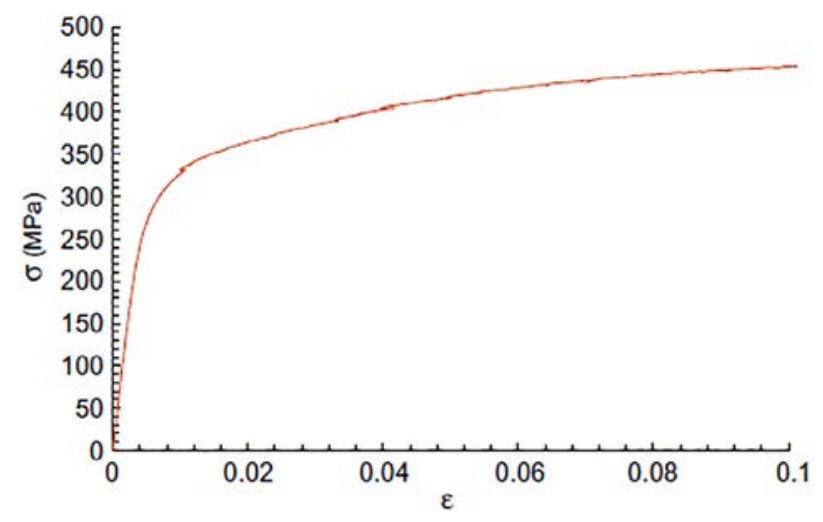

Fig. 7. Stress-strain curve of the Al. 2024-T3 plate [32].

Table 3

Mechanical properties of the adhesives used in this study [34].

\begin{tabular}{llll}
\hline Property & AV138 & 2015 & 7752 \\
\hline Young's modulus, E (GPa) & $4.89 \pm 0.81$ & $1.85 \pm 0.21$ & $0.49 \pm 0.09$ \\
Poisson's ratio, $\nu$ & 0.35 & 0.33 & 0.30 \\
Tensile yield stress, $\sigma_{\mathrm{y}}(\mathrm{MPa})$ & $36.49 \pm 2.47$ & $12.63 \pm 0.61$ & $3.24 \pm 0.48$ \\
Tensile strength, $\sigma_{\mathrm{f}}(\mathrm{MPa})$ & $39.45 \pm 3.18$ & $21.63 \pm 1.61$ & $11.48 \pm 0.25$ \\
Tensile failure strain, $\varepsilon_{\mathrm{f}}(\%)$ & $1.21 \pm 0.10$ & $4.77 \pm 0.15$ & $19.18 \pm 1.40$ \\
Shear modulus, G $(\mathrm{GPa})$ & $1.56 \pm 0.01$ & $0.56 \pm 0.21$ & $0.19 \pm 0.01$ \\
Shear yield stress, $\tau_{\mathrm{y}}(\mathrm{MPa})$ & $25.1 \pm 0.33$ & $14.6 \pm 1.3$ & $5.16 \pm 1.14$ \\
Shear strength, $\tau_{\mathrm{f}}(\mathrm{MPa})$ & $30.2 \pm 0.40$ & $17.9 \pm 1.8$ & $10.17 \pm 0.64$ \\
Shear failure strain, $\gamma_{\mathrm{f}}(\%)$ & $7.8 \pm 0.7$ & $43.9 \pm 3.4$ & $54.82 \pm 6.38$ \\
Toughness in tension, $\mathrm{G}_{\mathrm{IC}}$ & 0.20 & $0.43 \pm 0.02$ & $2.36 \pm 0.17$ \\
$\quad(\mathrm{~N} / \mathrm{mm})$ & & & \\
Toughness in shear, $\mathrm{G}_{\mathrm{IIC}}$ & 0.38 & $4.70 \pm 0.34$ & $5.41 \pm 0.47$ \\
$\quad(\mathrm{~N} / \mathrm{mm})$ & & &
\end{tabular}

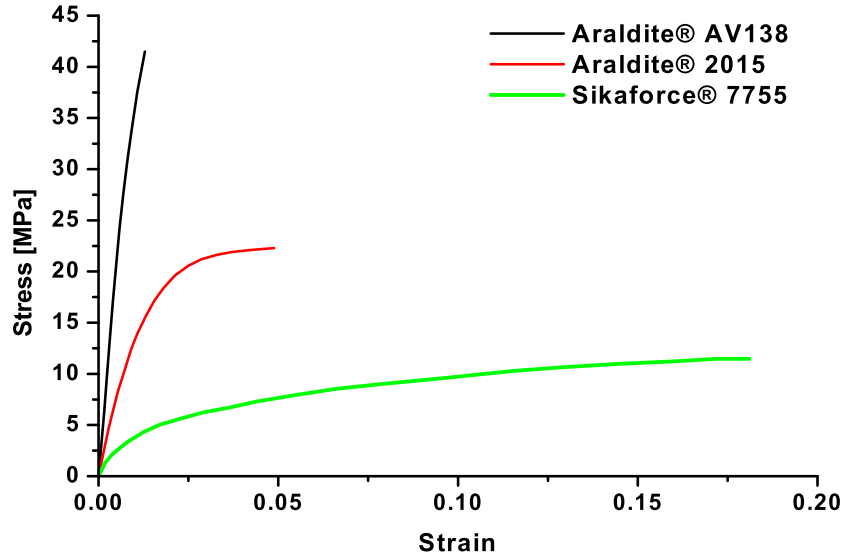

Fig. 8. Tensile stress-strain curves of the analyzed adhesives [34].

mate stress has been exceeded. The plasticity model takes into accountstresses above the ultimate stress.

In order to demonstrate the effect of the nature of the interface on the repair degradation process related to the failure of the interfacial bonds of the patch/adhesive/plate assembly, i.e. to predict the debonding of the patch from the plate, three adhesives were chosen, Araldite AV138, Araldite 2015 and Sikaforce 7752, which have distinct mechanical tensile strength (Table 3, Fig. 8). The first two adhesives have diametrically opposite behavior, the first is stiff and quasiviscoelastic and its tensile deformation at rupture is close to $(2.5 \%)$. The second one is ductile and is characterized by a non-linear viscoelastic behavior and a much wider viscoplastic range. So, it has an intermediate behavior whose viscoplastic deformation at tensile fracture $(5 \%)$ is about 3.7 less than that of the third (18.5\%) of Sikaforce 7752, which has a totally viscoplastic behavior (Fig. 8). Modelling the damage to the interfacial adhesive joint, responsible for the debonding of the composite patch, requires the failure parameters of these adhesives to be taken into account (Tab. 3).

\section{Analysis and results}

The purpose of this work is to predict the adhesive damage responsible for the degradation of composite patch repair of patch/adhesive/plate assemblies, the development of physical parameters indicative of interfacial damage and the interaction between these parameters and the adhesive properties of the interface and the competition between two damage mechanisms: interfacial damage by adhesive failure in terms of initiation and propagation of debonding, and damage to the repaired plate by growth of notch cracks. Simulations, based on the combination of two extended finite element approaches (XFEM) and the cohesive zone model (CZM) were developed to achieve this objective.

\subsection{Adhesive damage parameters}

The adhesive, ensuring the patch-zone junction of the plate weakened by the notch effect, generally has sufficiently low fracture energies (Tab.3). It is therefore the weakest link in the patch-adhesiveplate chain. It is clear that the separation energy $G_{I}, G_{I I}$ and $G_{I I I}$ in modes I, II and III of the adhesives is a determining parameter of the resistance to debonding. These parameters are taken into account when modelling the degradation of patch/adhesive/plate assemblies in terms of interfacial (adhesive) damage, i.e. in terms of patch debonding.

It should be remembered that in the case of repair, the adhesive has to satisfy two fundamental conditions: ensuring the good mechanical strength of the patch-plate joint and the good load transfer from the 


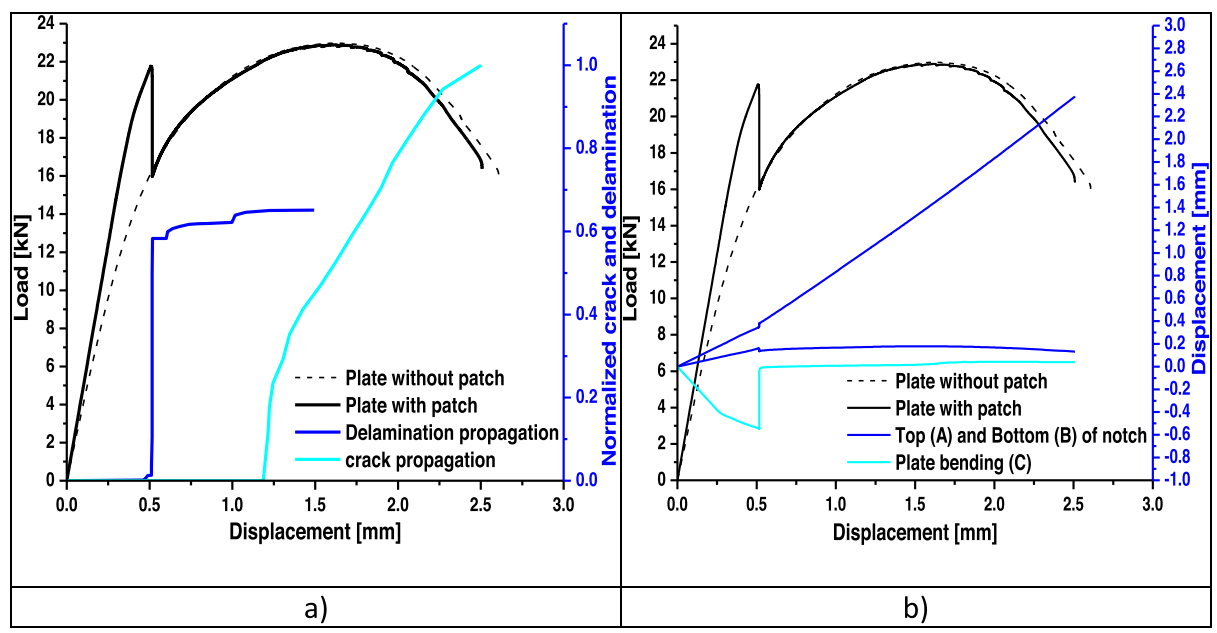

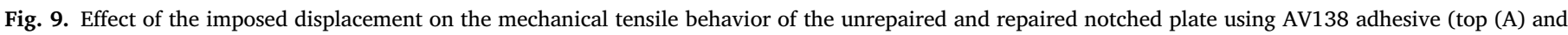
bottom (B) of notch see Fig. 5).

damaged plate to the patch. To meet these conditions, the mechanical and geometrical properties of the adhesive must be optimized [7].

The results obtained from this analysis and shown in Fig. 9 show clearly that the presence of the patch, assembled to the plate using a linear quasi-viscoelastic adhesive (Araldite AV138, Fig. 8), leads to the reinforcement of the stiffness of the plate initially weakened by the notch effect (Fig. 9a). Thus, the resistance to debonding of the patch from the plate overcomes after an imposed displacement of the order of $0.5 \mathrm{~mm}$ (Fig. 9a). At this displacement, this resistance drops brutally and the mechanical tensile strength of the plate with patch tends towards that of the unrepaired plate. This fall is characteristic of the beginning of the patch debonding by rupture of the adhesive layer, and its propagation is accompanied by the initiation and growth of notched cracks (Fig. 9a). This behavior, observed after a displacement of approximately $1.2 \mathrm{~mm}$ (Fig. 9a), is characteristic of the total separation of the patch from the plate. Another parameter, characteristic of adhesive damage due to the rupture of the plate-patch bonding forces, highlighted in this study, is the elastic buckling of the repaired notched plate due to the normal compressive stress causing the transition from a state of compression to a state of bending. The relaxation of this buckling, induced by the high stiffness of the patch, is a parameter indicative of the initiation and propagation of debonding (Fig. 9b). Indeed, the bending, generated by the local bending of the reinforced plate, initially with an amplitude of $-0.55 \mathrm{~mm}$, is cancelled after a displacement imposed on the assembly of $0.5 \mathrm{~mm}$ (Fig. 9b). This behavior shows that the dissipation of the elastic deformation due to buckling is a physical parameter revealing the damage of the adhesive by breaking the patch/plate interfacial bonding forces. This parameter allows adequate prediction of repair damage in terms of dissipation of interfacial adhesion energy of the patch/adhesive/plate assembly by interfacial decohesion due to adhesive damage by a mechanism of initiation and propagation of debonding (Fig. 9b).

A third parameter of adhesive damage, developed in this study, is the displacement trajectory of the repaired plate during the tensile process. The point at which this trajectory is deviated, characterized by an increase in its angle, initially small, is a parameter for predicting adhesive degradation by a mechanism of initiation and propagation of the debonding responsible for the patch/plate interfacial rupture. This point, characteristic of an acceleration of the deformation kinetics of the patch-reinforced plate, effectively corresponds to the initiation of the debonding of the patch from the plate. This acceleration, defined by an increase in the angle of the displacement trajectory, is observed when the imposed displacement reaches $0.5 \mathrm{~mm}$ (Fig. 9b). At this point, total dissipation of the debonding resistance, complete relaxation of the bending deflection of the repaired plate, and relaxation of the shear stresses is achieved. This annihilation of these four physical mechanisms is characteristic of the adhesive damage responsible for the decohesion of the patch/adhesive/plate assembly.

Although, due to its high stiffness (Fig. 8, Tab. 3), the Araldite AV138 adhesive gives the patch-plate assembly a high adhesive energy, it nevertheless constitutes a barrier to the transfer of load from the notched plate to the patch. In this case, a high proportion of this load is stored in the adhesive layer in the form of high intensity shear stresses, induced in the plane of adhesion yoz (Fig. 10). It is clearly defined in this figure that the maximum stresses are located at the

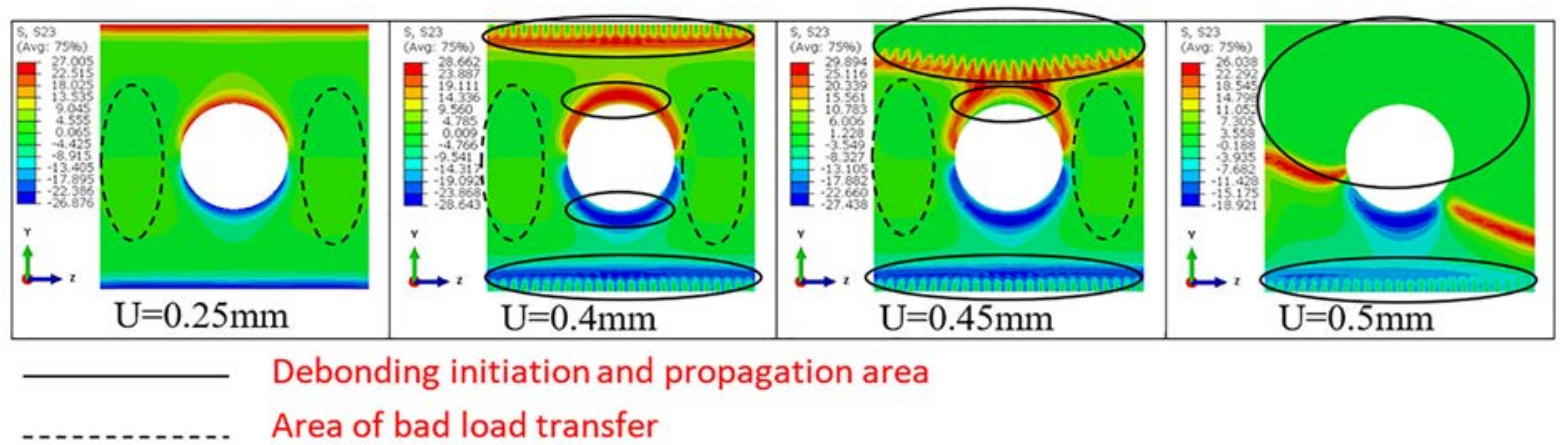

Fig. 10. Shear stress in araldite AV138 adhesive with different imposed displacements. 
edges of the adhesive with the patch and with the notch. These two sites therefore constitute a preferential site for initiation and propagation of interface damage (debonding) as shown in Fig. 10. This phenomenon is accompanied by total relaxation of these shear stresses. The dissipation of these stresses, corresponding to the green color, takes place after an imposed tensile displacement " $\mathrm{U}=0.5 \mathrm{~mm}$ " on the repaired plate (Fig. 10).

Debonding begins at the plate-patch interface at the free edges of the plate/adhesive/patch assembly and at the notch-patch edge, corresponding to the elliptical area shown in a continuous line (Fig. 10). Under the effect of the larger imposed displacements, the plate-patch debonding spreads (green colored area) and leads to the total degradation of the plate-patch bond, characterized by a zero-shear stress level.

It should be noted, however, that in the case of a repair using a rigid viscoelastic adhesive (Araldite AV138), for small imposed displacements, the green areas located on the lateral edges of the adhesive, represented by a discontinuous elliptical shape (Fig. 10), correspond to areas of poor load transfer from the notched plate to the composite patch through the adhesive layer and not to debonding areas.

This part of the work allowed the development of four physical quantities indicative of debonding in the case of composite patch repair of structures weakened by the presence of discontinuities, i.e. in the case of patch/adhesive/plate assemblies: the strength of the patch debonding from the plate, the local bending deflection of the plate, the path of movement of the plate and the shear stresses at the interface. The individual and simultaneous interaction between these parameters was highlighted in this part of the work. In conclusion, these physical quantities allow adequate prediction of the interfacial degradation of patch/adhesive/plate assemblies.

It would be relevant to analyze the interaction effects between these four parameters indicative of adhesive damage and the adhesive properties of the patch/adhesive/plate assembly interface.

\subsection{Damage parameter-interaction}

The previous study allowed the development of four physical parameters to predict the damage of the interface (adhesive) bonding the patch to the notched plate. It is useful to predict the interactions between these parameters and the adhesive properties of the interface between the patch and the plate. For this purpose, three interfaces, according to their mechanical characteristics (Fig. 8, Tab. 3), were selected for this study. Debonding, resulting from interface damage, occurs instantaneously when the repair is carried out using a viscoelastic, quasi-fragile adhesive with high stiffness and high failure criteria (Fig. 9,10).

In the case of the use of viscoplastic adhesives, case of Araldite 2015, the degradation of the resistance to debonding, resulting from interfacial damage, begins after a much greater imposed displacement of the order of $1.5 \mathrm{~mm}$ (Fig. 11c). This corresponds perfectly, in our

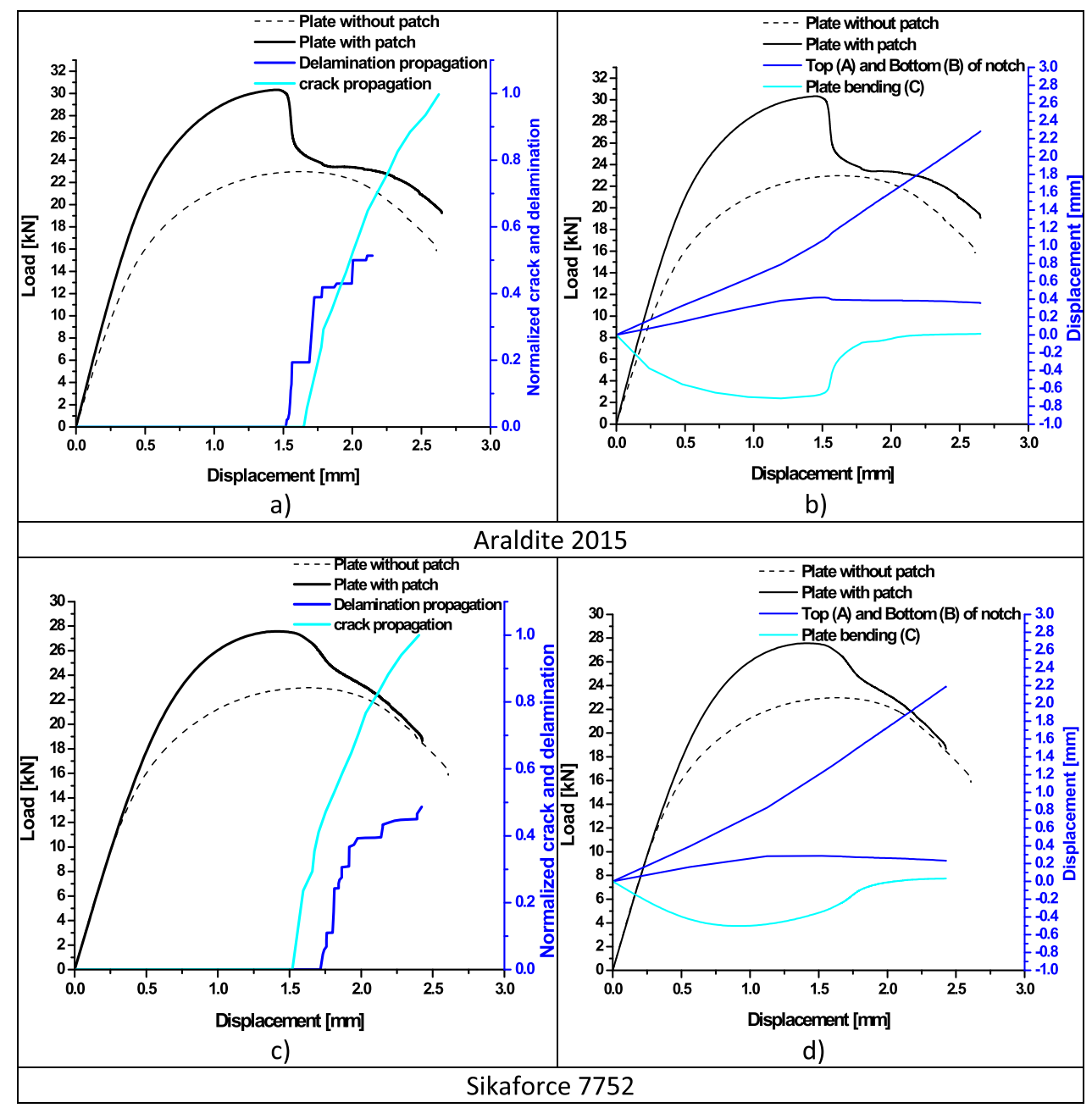

Fig. 11. Effect of the adhesive properties of the interface on the tensile behavior of the repaired notched plate. 
case, to the total relaxation of the bending forces generated by the high stiffness of the composite patch bonded to the notched plate (Fig. 11b). This value corresponds to a bending deflection with an amplitude of $-0.7 \mathrm{~mm}$. Beyond this displacement $(\mathrm{U}=1.5 \mathrm{~mm}$ ), the amplitude tends towards zero. This behavior is characteristic of the reversibility of the elastic deformation due to buckling of the repaired plate (Fig. 11b). This dissipation of the elastic energy of buckling is indicative of the damage to the adhesive due to the degradation of the interfacial links by initiation and propagation of the debonding of the patch from the plate. It should be noted that this displacement $(1.5 \mathrm{~mm})$ corresponds to the point at which the evolution of the angle of the displacement trajectory takes place during the traction of the repaired plate. This explicitly shows that the point at which the acceleration of the plate displacement speed occurs is a parameter indicating the failure of the adhesive joint responsible for the interfacial decohesion of the patch/adhesive/plate assembly by a debonding mechanism (Fig. 11b).

Beyond this imposed displacement $(1.5 \mathrm{~mm})$, the resistance to debonding of the patch drops almost brutally and the mechanical tensile strength of the repaired plate follows that of the structure without the patch (Fig. 11a, b). This drop, linked to the total dissipation of the interfacial cohesion energy of the patch/interface/plate assembly, is accompanied, after an imposed displacement of $1.6 \mathrm{~mm}$, by the initiation and propagation of cracks emanating from notches in the repaired plate (Fig. 11a). This behavior clearly illustrates that the relaxation of the buckling forces, defined by a total absence of the bending deflection (zero deflection) of the repaired plate (Fig. 11b), and the point at which the evolution of the displacement path angle occurs during the traction process of the structure (Fig. 11b), are two physical parameters characteristic of the adhesive layer damage in terms of initiation and propagation of the debonding.

After an imposed displacement of $1.5 \mathrm{~mm}$, an almost complete relaxation of the tangential stresses in the adhesive joint is observed (Fig. 12). This dissipation, defined by a level of shear stresses that is almost zero, corresponds to the green color in Fig. 12, is a characteristic quantity of the damage of the (adhesive) interface of the patch/interface/plate assemblies. Damage to the adhesive by breaking of the cohesive forces remains the main cause of the process of debonding the patch from the plate. Damage to the repaired plate occurs by fracture of the interfacial bonding forces (debonding) and by initiation and propagation of notched cracks. Debonding begins at the free edges with the patch and with the notch and propagates simultaneously from these two sites (Fig. 12). Due to its viscoelastoplasticity, Araldite 2015 induces shear stresses at a lower level than those resulting from the Araldite AV138.

These results show that, after an imposed displacement of $1.5 \mathrm{~mm}$, four physical phenomena, the drop in debonding resistance, the reversibility of the elastic deformation due to buckling of the repaired plate, the evolution of the trajectory angle and the relaxation of the shear stresses in the adhesive joint, occur simultaneously. These physical parameters, which are characteristic of interface damage, make it possible to predict damage to patch/adhesive/plate assemblies by adhesive failure. In other words, these quantities are parameters indicative of composite patch debonding from the plate.

The non-linear tensile behavior of the plate repaired with Araldite 2015, observed after an imposed displacement of $0.5 \mathrm{~mm}$, shows that this structure has plastically deformed (Fig. 11a, b). We return to this point later. In such a case, part of the tensile stress applied to the repaired plate, transmitted to the adhesive in the form of shear stresses, is stored by this material in the form of irreversible viscoplastic deformation. This seems to explain the damage to the adhesive by viscoplastification without separation of the patch from the plate. This deformation is responsible for the rupture of the patch/plate interfacial bonding forces and the dissipation of interfacial adhesion energy.

The Sikaforce 7752 adhesive exhibits greater viscoplastic deformation at tensile failure than other adhesives (Fig. 8). In the case of a repair using this adhesive, the gradual and slow decline in debonding resistance is initiated after an imposed displacement of approximately $1.25 \mathrm{~mm}$. This drop, due to adhesive damage, is accompanied, when the displacement reaches $1.5 \mathrm{~mm}$, by the initiation and growth of cracks emanating from notches in the repaired plate well before patch-plate separation (Fig. 11c). This displacement is in good agreement with the progressive dissipation of the initial $-0.5 \mathrm{~mm}$ amplitude deflection and the evolution of the angle of the plate displacement trajectory. Thus, full separation (debonding) of the patch from the plate occurs once the displacement imposed on the patch/adhesive/plate assembly reaches $1.75 \mathrm{~mm}$ (Fig. 11c). This displacement $(1.75 \mathrm{~mm})$ corresponds well to the end of the slow relaxation process of the local bending deflection and to the end of the drop in plate patch debonding resistance (Fig. 11d). At this displacement $(1.75 \mathrm{~mm})$, the patch has completely detached the notched plate. The near-zero shear

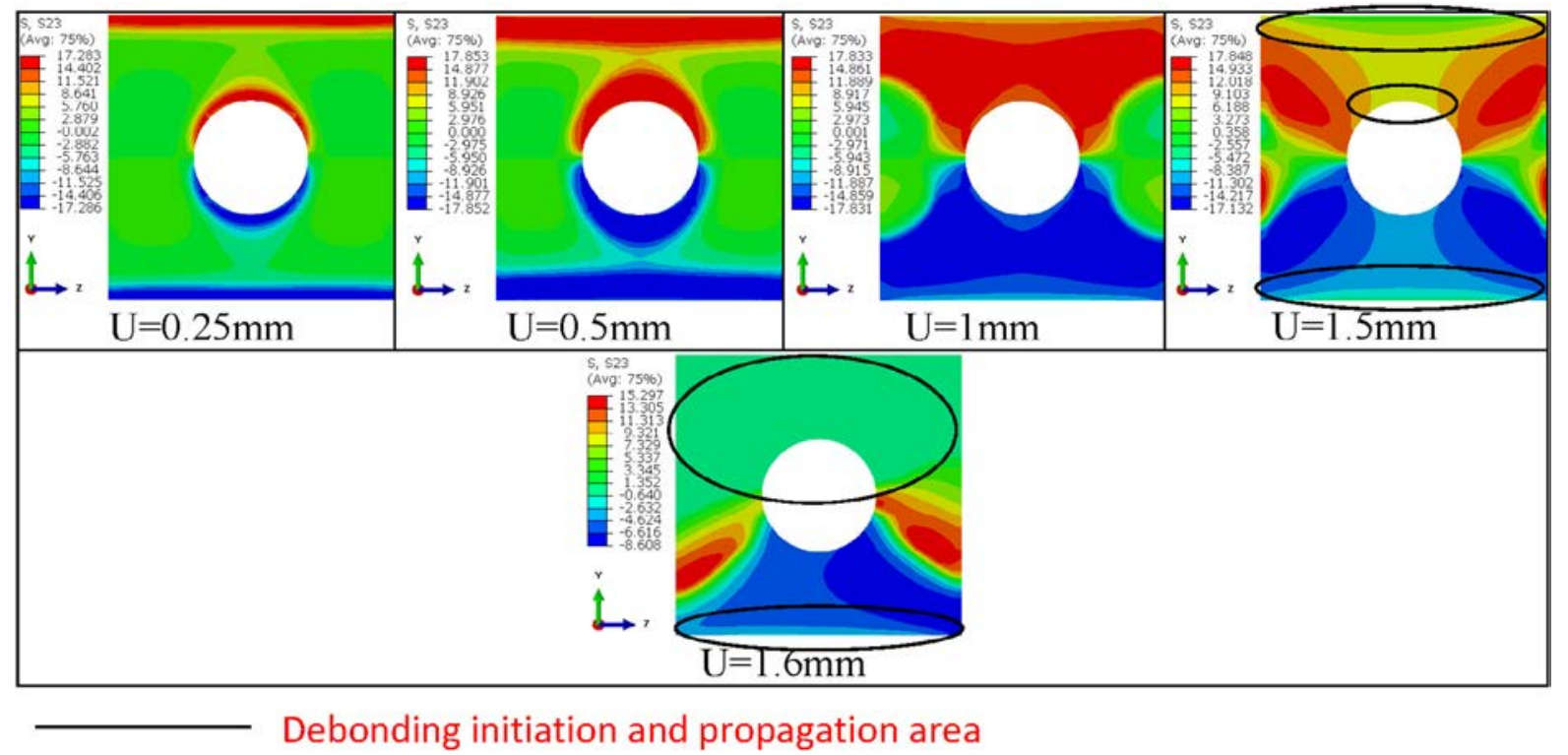

Fig. 12. Shear stress in Araldite 2015 adhesive with different imposed displacements. 


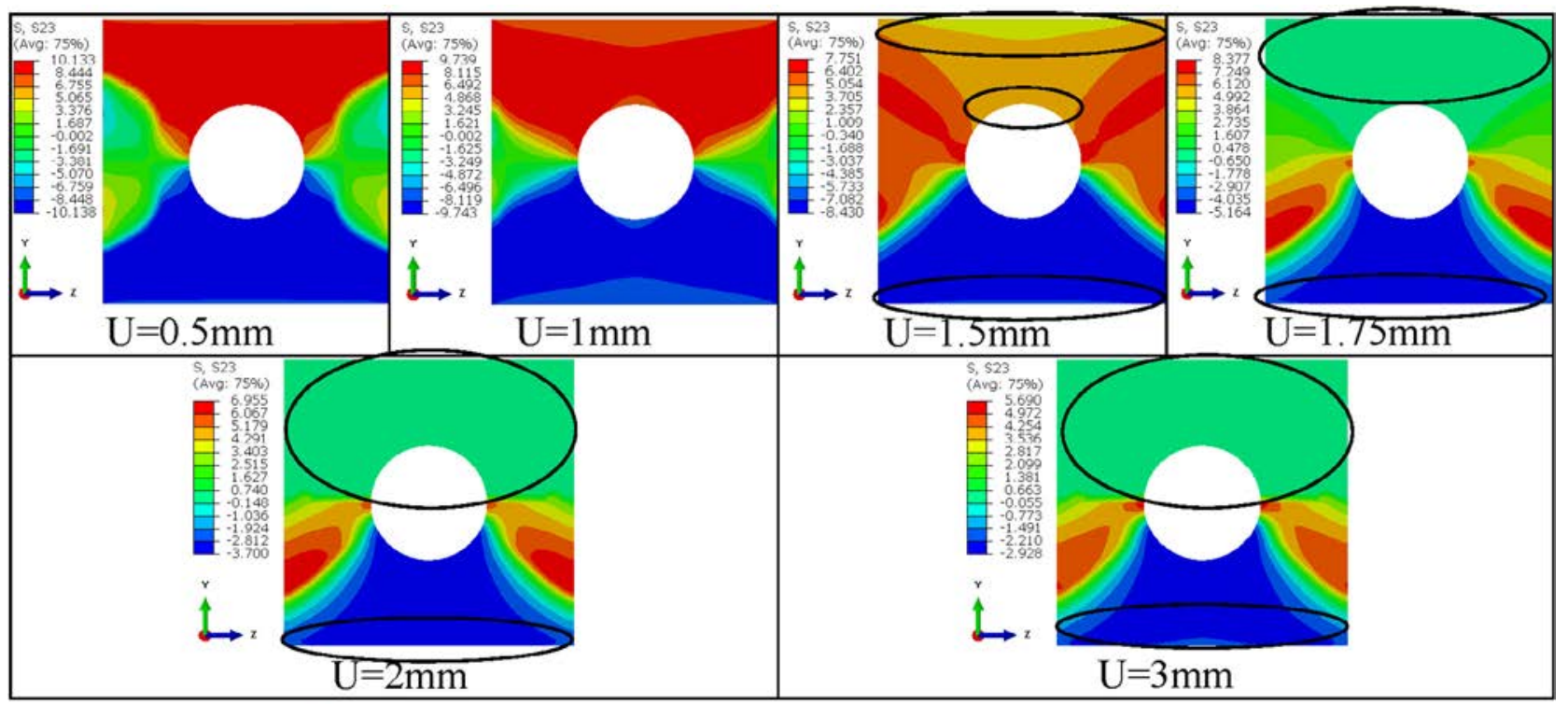

\section{Debonding initiation and propagation area}

Fig. 13. Shear stress in Sikaforce 7752 adhesive with different imposed displacements.

stresses observed in the adhesive (green color) explicitly illustrate the total degradation of the adhesive layer, which was the main cause of the patch debonding (Fig. 13).

In contrary to Araldite 2015, the Sikaforce 7752 adhesive, which has a non-linear viscoelastoplasticbehavior, a wider viscoplastic range (Fig. 8) and a viscoplastic deformation at tensile fracture approximately 3.7 times greater, the relaxation of these two physical phenomena (dissipation of bending stresses and drop in debonding resistance) occurs over time (Fig. 11d). The plate, repaired with this adhesive, is damaged by initiation and propagation of notch cracks after the adhesive failure by viscoplastification and well before patch-plate separation. In fact, cracks begin after an imposed displacement of the order of $1.5 \mathrm{~mm}$ and the debonding of the patch from the plate begins at a displacement of $1.75 \mathrm{~mm}$ (Fig. 11c). The viscoplasticity damage of the adhesive, generated during the traction process of the repaired plate, is responsible for this behavior.

In the case of the viscoelastic adhesive, Araldite AV138, once the debonding resistance has been passed and in the absence of any viscoplasticization of the adhesive, the patch debonded and detached brutally from the plate, which explains the tendency of the mechanical tensile strength of the repaired plate to that of the unrepaired plate. Contrary to this behaviour, in the case of the viscoelastoplastic adhesives, Araldite 2015 and Sikaforce 7752, the patch debonding from the plate but remains attached to the notched surface. The viscoplasticization of these adhesives, under the effect of imposed displacements, is responsible for this behaviour. This non-separation of the patch from the plate is the cause of the difference observed (Fig. 11a) between the mechanical tensile strength of the repaired plate and that of the unrepaired plate.

The results of this analysis adequately confirm those obtained previously (case of the adhesive Araldite AV138 and Araldite 2015) and show that the physical quantities (patch debonding resistance, bending deflection of the repaired plate, the angle of the displacement path of the repaired plate and the shear stresses in the adhesive) are indeed parameters indicative of the adhesive damage responsible for the degradation of the patch/adhesive/plate assemblies. They also show that their behavior is closely related to the adhesive properties of the interface.

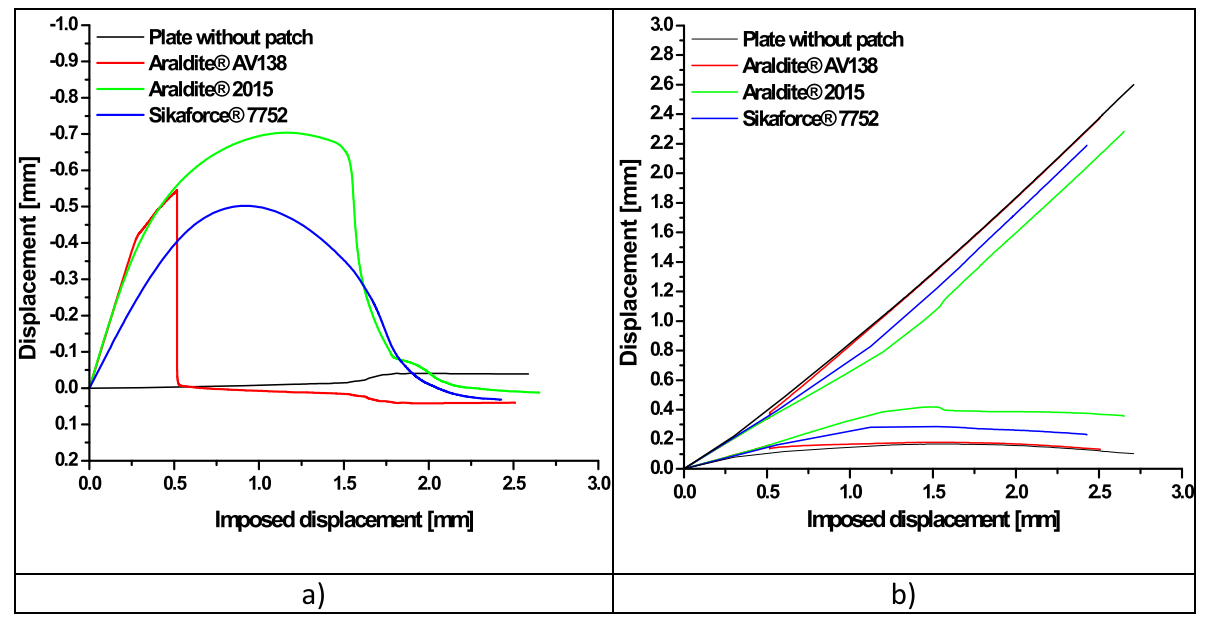

Fig. 14. Effect of the adhesive properties of the interface on a) path of reversibility of elastic deformation due to buckling b) path of movement of the repaired plate. 


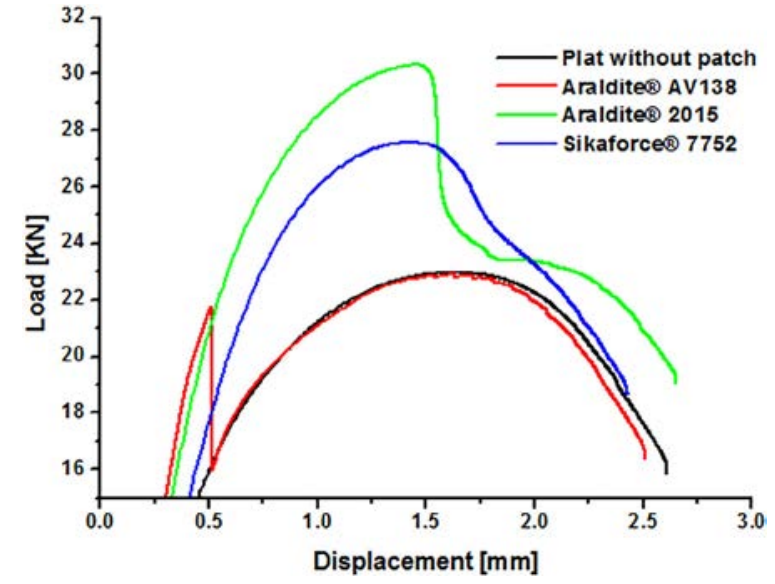

Fig. 15. Effect of interface adhesive properties on patch/plate debonding resistance.

Compared to the viscoelastic adhesive Araldite AV138, leads to a linear abrupt drop in the patch debonding resistance, a linear instantaneous relaxation of the bending deflection (Fig. 14b), and an early point where the evolution of the angle to the line of travel of the repaired plate takes place (Fig. 14a), in the case of the viscoelastoplastic Araldite 2015 and Sikaforce 7752 adhesives, the degradation of the mechanical strength at debonding (Fig. 14) and the relaxation of the deflection follow a long non-linear path, and the point at which the acceleration of the plate displacement kinetics takes place is more delayed (Fig. 15).

The non-linearity of the reversibility too slow of the elastic deformation (bending deflection) due to buckling of the repaired plate, the delay in the point of change of the displacement trajectory of the repaired plate and the non-linearity of the patch/plate interfacial resistance observed in the case of a repair using Araldite 2015 and Sikaforce 7752 (Figs. 14, 15), are essentially due to the viscoplastic deformation of these two adhesives.

Viscoplastification of the adhesive by extending the macromolecular chains accelerates the damage but delays patch/plate separation. This patch/plate separation takes place after significant irreversible deformation.

The non-symmetry, with regards to the transverse axis of the notch, of the movement paths of the upper and lower parts and of the shear stresses in the adhesive joint is mainly due to the embedding effect of the lower part of the plate.

The results obtained previously show that the ruin of the composite patch repair bonded to the area damaged by the notch effect of the aircraft plates, i.e. of the plate/adhesive/patch assembly, is essentially due to interfacial damage of the adhesive layer by a mechanism of initiation and propagation of the plate/patch debonding. It is clearly defined (Figs. 10, 12 and 13) that regardless of the interfacial adhesive properties of the plate/adhesive/patch assemblies, debonding starts at the plate-patch interfacial at the free edge of the assembly and at the notch-patch edge. Damage to the adhesive responsible for debonding occurs almost instantaneously, i.e. at extremely small displacements when the plate is bonded to the patch using a viscoelastic adhesive (Araldite AV138) and at more significant displacements if the adhesive exhibits viscoplastic behaviour (Araldite 2015, SikaForce 7752) (Figs. 10, 12 and 13). This clearly shows that the viscoplasticization of the interfacial adhesive slows down the separation of the patch from the plate. The total relaxation of shear stresses, after large imposed displacements, is characteristic of this behaviour.

The non-symmetry of the lower (adhesive) part of the repaired area is mainly due to the embedding effect (boundary conditions) of the lower part of the plate.

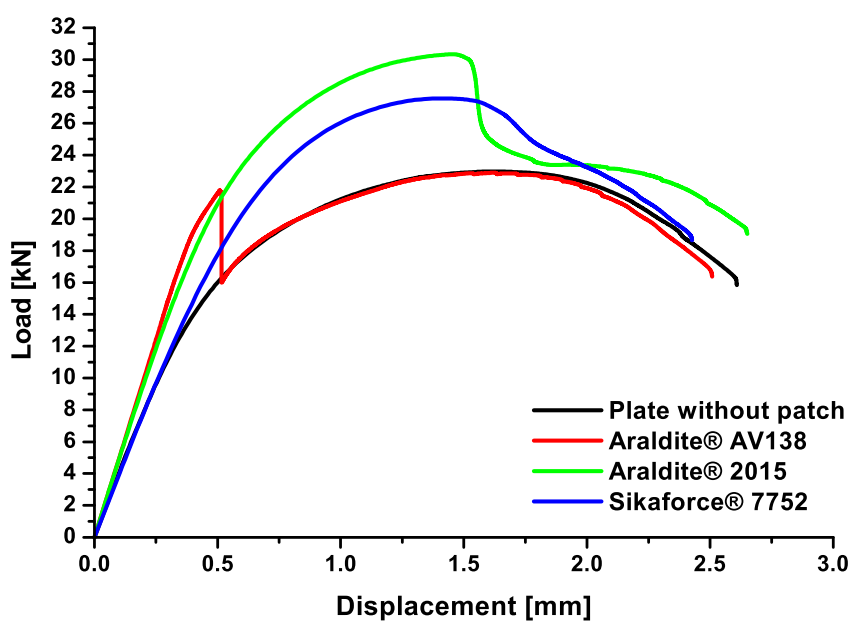

Fig. 16. Effect of the adhesive properties of the interface on the tensile behavior of patch/adhesive/plate assemblies.

\subsection{Adhesive-plate interaction}

In this part of the study, Fig. 16 shows a comparative analysis of the tensile behavior of patch/adhesive/plate connections as a function of the nature of the interface. The viscoelastic adhesive, Araldite AV138, leads to a better efficiency of the repair in terms of stiffness, it is responsible for the initiation and brutally propagation of the patch debonding by a brittle rupture of the interfacial bonds. This phenomenon, observed after an imposed displacement of $0.5 \mathrm{~mm}$ (Figs. 13, 14), is thus accompanied by plate plasticization (Fig. 13) and its rupture by a mechanism of initiation and growth of notched cracks after a displacement of approximately $1.2 \mathrm{~mm}$ (Fig. 15). The non-linear behavior of the repaired plate observed is characteristic of adhesive damage (Fig. 13).

In the case of the viscoelastoplastic adhesive, the non-linearity of the mechanical behavior of the plate, repaired using this adhesive, observed after a displacement of $0.5 \mathrm{~mm}$ clearly shows that this structure has undergone irreversible deformation. Beyond this displacement, the damage of the adhesive by viscoplastification (Fig. 8) and the good load transfer through the adhesive during the first moments of traction, cause a delay in the process of separation of the patch from the plate. A displacement larger than $0.5 \mathrm{~mm}$ leads to simultaneous plastification of the plate and viscoplastification of the adhesive bond (Fig. 16). This double plastification is responsible for increasing the tensile strength of the patch/adhesive/plate assembly for imposed displacements of up to $1.5 \mathrm{~mm}$ (Fig. 16). Beyond this displacement, the damage to the adhesive joint, related to the rupture of the interfacial cohesive bond, causes the patch to separate completely from the plate (debonding), which is responsible for the gradual fall in mechanical resistance to debonding. This drop observed after an imposed displacement of the order of $1.5 \mathrm{~mm}$, is accompanied by the initiation and propagation of notched cracks leading to plate failure (Fig. 17).

The non-linear Sikaforce 7752 viscoelastoplastic adhesive does not improve the rigidity of the notched plate under any circumstances (Fig. 16). Damage to the repaired plate by initiation and growth of notch-induced cracks occurs, after an imposed displacement of $1.5 \mathrm{~mm}$ (Fig. 17a), well before initiation of debonding, which occurs after a displacement of $1.75 \mathrm{~mm}$ (Fig. 17b).

The results shown in Fig. 17a, b explicitly show that, depending on the adhesive properties of the interface, the damage mechanisms of the composite patch repair, i.e. patch/adhesive/plate assemblies, compete with each other. Our results show that the predominant degradation mechanism between adhesive damage, related to the failure of interfacial bonding forces in terms of debonding, and the failure of the patch repaired plate by initiation and propagation of notch- 


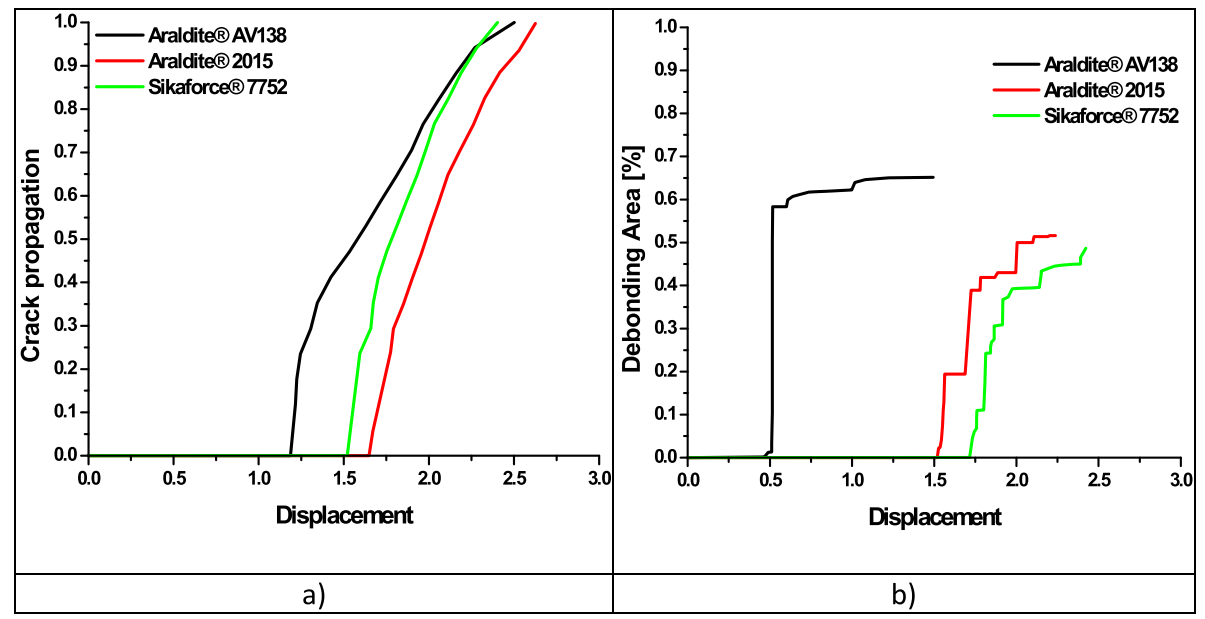

Fig. 17. Effect of the adhesive properties of the interface on: a) crack propagation and b) initiation of patch debonding.

induced cracks is closely related to the adhesive properties of the interface (Fig. 17a, b). Thus, there is an interaction between the notch embrittled plate and the nature of the interface that allows prediction of the predominant failure mechanism of these assemblies. Indeed, in the case of repairs using viscoelastoplastic interfaces, with a wider viscoplastic range, low shear mechanical characteristics, high shear fracture strain and low $\mathrm{G}_{\mathrm{II}}$ and $\mathrm{G}_{\mathrm{III}}$ shear fracture energies, failure of patch/adhesive/plate assemblies is preferentially due to damage to the plate by a mechanism of crack initiation and growth emanating from discontinuity (notch) (Fig. 17a). The development of these cracks perpendicular to the direction of the imposed displacements leads to the initiation and propagation of the debonding responsible for the total debonding of the patch from the plate by adhesive failure
(Fig. 17b). On the contrary, the predominant mechanisms of degradation of patch/adhesive/plate systems where the repair is performed using quasi-viscoelastic or viscoelastoplastic adhesives, with a restricted viscoplastic range, relatively high modulus and shear strength, low shear strain and relatively high $\mathrm{G}_{\mathrm{II}}$ and $\mathrm{G}_{\mathrm{III}}$ shear failure criteria, correspond to the initiation and propagation of the debonding related to adhesive damage by rupture of the interfacial bonds (Fig. 17b). Debonding is followed by plate damage through crack initiation and development (Fig. 17a).

It was clearly shown in this work that the damage of the adhesive joint, interposed at the notched plate-patch interface, is responsible for the separation (debonding) of these two protagonists jointly linked and thus for the ruin of the plate/adhesive/patch assemblies, i.e. the

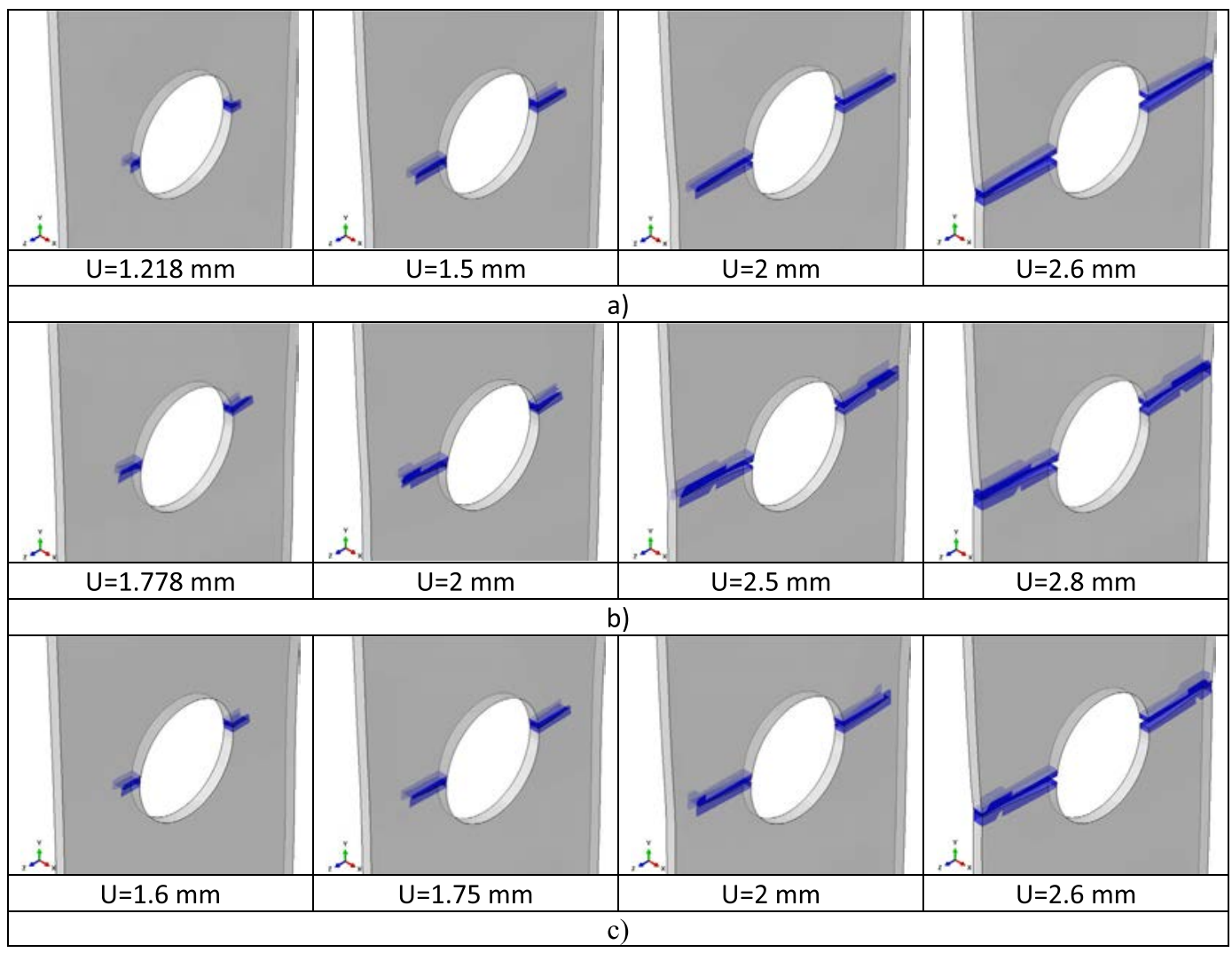

Fig. 18. Cracking surface in the notched plate with different adhesives:a) Araldite AV138, b) Araldite 2015 and c) SikaForce 7752 in function of imposed displacements. 
degradation of the repair. This debonding results in the damage of the repaired plate by a mechanism of initiation and propagation of notched cracks (Fig. 18). This figure shows that the cracks, initiated at the bottom of the notch, develop with increasing displacement along the plate and lead to its total degradation.

\section{Conclusion}

The results obtained in this study lead to the conclusion that:

- Modelling based on the combination of these two methods (XFEM and CZM) leads to a reliable analysis of the repair failure in terms of adhesive damage by an interfacial debonding phenomenon of plate/ adhesive/patch system. This modeling has allowed the demonstration of the interaction of two physical phenomena of patch/adhesive/plate system damage: initiation and development of debonding and initiation and propagation of notch cracking. These two phenomena are in competition, depending on the physical properties of the interface;

- The 3D modelling of the damage, based on the simultaneous use of the two approaches XFEM and CZM, of the patch/adhesive/plate system highlights four physical parameters indicative of interfacial debonding: debonding resistance, plate bending deflection, plate displacement trajectory and shear stresses in the adhesive. Interactions between these parameters, indicative of interfacial damage to the system (debonding of the patch) and crack initiation and propagation emanating from notches in the repaired plate are potential indicators of patch separation from the plate.

-This modeling explicitly illustrates that debonding is a physical phenomenon closely related to the adhesive properties of the interface:

- A stiff interface (quasiviscoelastic adhesive), defined by a virtual absence of viscoplastic deformation at tensile failure, strong mechanical properties and high breaking criteria, degrades brutally. The instantaneous and linear drop in debonding strength (patch/plate separation), local bending deflection, interfacial shear stresses and premature change of the displacement path are accompanied by damage to the repaired plate by a priming mechanism and notch cracking;

- An extremely ductile interface (non-linear viscoelastic adhesive) with an extended viscoplasticizing range, characterized by low mechanical properties (low tensile and shear fracture stresses, low stiffness, high tensile fracture strain, low energy restitution rate in modes I, II and III), gradually damages. The gradual, slow, nonlinear decrease in debonding strength, buckling stress, interfacial tangential stresses, and the too-delayed change in plate travel path results in notch crack initiation and propagation well before the initiation of plate patch debonding;

- A ductile interface (viscoelastoplastic adhesive), defined by a low viscoplastification range, characterized by intermediate properties between a rigid interface and an extremely ductile interface, degrades more slowly than a rigid interface, but rapidly than an extremely ductile interface. The relatively slow and non-linear degradation of the debonding strength, plate bending stresses, shear stresses, and variation in the path of displacement of the plate is accompanied by damage to the repaired plate by a mechanism of initiation and growth of notch-induced cracks. This cracking occurs after the patch is debonded from the plate.

- Damage modeling of patch/adhesive/plate assemblies, independent of the nature of the interface, predicts that the free edges with the composite patch and with the notch are preferred sites of interfacial damage by cohesive bond force failure. Patch debonding initiates and propagates from these sites. These are the sites of maximum shear stresses induced in the adhesive layer during the tensile process of the assembly. This modeling was used to predict that separation of the repaired plate patch results in relaxation of these stresses. The level of these stresses is directly related to the nature of the interface. Rigid interfaces induce higher stresses and are subject to the risk of damage by cohesive brutal rupture.

Globally, modelling of the fracture behavior of structures repaired by composite patch, based on the combined use of two approaches XFEM and CZM, has made it possible to predict the degradation of patch/adhesive/plate assemblies by interface damage, and the coupling mechanisms between patch debonding and notch crack propagation. This modeling revealed four physical parameters related to adhesive damage.

\section{CRediT authorship contribution statement}

Mohammed Amine Bellali: Conceptualization, Methodology, Software, Investigation, Writing - original draft, Writing - review \& editing. Boualem Serier: Conceptualization, Methodology, Writing original draft, Writing - review \& editing, Supervision. Mohamed Mokhtari: Conceptualization, Methodology, Software, Investigation. Raul D.S.G. Campilho: Writing - review \& editing. Frederic Lebon: Writing - review \& editing. Hamida Fekirini: Writing - review \& editing.

\section{Declaration of Competing Interest}

The authors declare that they have no known competing financial interests or personal relationships that could have appeared to influence the work reported in this paper.

\section{References}

[1] Makwana AH, Shaikh AA, Bakare AK, Chitturi S. Investigation of patch hybridization effect on the composite patch repair of a cracked aluminum plate: A pragmatic approach. Mech Adv Mater Struct 2018;1-11. https://doi.org/ 10.1080/15376494.2018.1432818.

[2] Liao Y, Li Y, Huang M, Wang B, Yang Y, Pei S. Effect of hole relative size and position on crack deflection angle of repaired structure. Theor Appl Fract Mech 2019. https://doi.org/10.1016/j.tafmec.2019.02.010.

[3] Schubbe JJ, Bolstad SH, Reyes S. Fatigue crack growth behavior of aerospace and ship-grade aluminum repaired with composite patches in a corrosive environment. Compos Struct 2016;144:44-56. i.compstruct.2016.01.107.

[4] Khan Mohammed SMA, Mhamdia R, Albedah A, Bachir Bouiadjra BA, Bouiadjra $\mathrm{BB}$, Benyahia F. Fatigue crack growth in aluminum panels repaired with different shapes of single-sided composite patches. Int J Adhes Adhes 2021:102781. https:/ doi.org/10.1016/i.iiadhadh.2020.102781.

[5] Serier N, Mechab B, Mhamdia R, Serier B. A new formulation of the J integral of bonded composite repair in aircraft structures. Struct Eng Mech 2016;58 (5):745-55. , https://doi.org/10.12989/SEM.2016.58.5.745.

[6] Mhamdia R, Serier B, BachirBouiadjra B, Belhouari M. Numerical analysis of the patch shape effects on the performances of bonded composite repair in aircraft structures. Compos B Eng 2012;43(2):391-7. https://doi.org/10.1016/ i.compositesb.2011.08.047.

[7] Baghdadi M, Serier B, Salem M, Zaoui B, Kaddouri K. Modeling of a cracked and repaired Al 2024T3 aircraft plate: Effect of the composite patch shape on the repair performance. Frattura ed Integritàstrutturale 2019;50:68-85. https://doi.org/ 10.3221/IGF-ESIS. 50.08 .

[8] Bouchiba MSE, Serier B. A step towards the optimization of composite bonded repair shape using an estimation distribution approach. J Braz Soc Mech Sci Eng 2016;39(5):1755-71. https://doi.org/10.1007/s40430-016-0599-2.

[9] Albedah A, Khan Mohammed SMA, Bouiadjra BB, Bouiadjra BAB, Benyahia F. Effect of the patch length on the effectiveness of one-sided bonded composite repair for aluminum panels. Int J Adhes Adhes 2018;81:83-9. https://doi.org/ 10.1016/i. iiadhadh. 2017.11.012.

[10] Davis MJ. A call for minimum standards in design and application technology for bonded structural repairs. Proc Symp on Composite Repair of Aircraft Structures, Vancouver 1995;41:415.

[11] Denney JJ, Mall S. Characterization of disbond effects on fatigue crack growth behavior in aluminum plate with bonded composite patch. Eng Fract Mech 1997;57(5):507-25. https://doi.org/10.1016/s0013-7944(97)00050-7.

[12] Deheeger A. Etude des effets thermiques dans des joints collés Application à des structures renforcées par patchs composites. Thèse de Doctorat Université Blaise Pascal Clermont 2009;II:2009. 
[13] Megueni A, Bachir BB, Belhouari M. Disbond effect on the stress intensity factor for repairing cracks with bonded composite patch. Comput Mater Sci 2004;29 (4):407-13. https://doi.org/10.1016/j.commatsci.2003.11.001.

[14] Ouinas D, Serier B, BachirBouiadjra B. The effects of disbonds on the pure mode II stress intensity factor of aluminium plate reinforced with bonded composite materials. Comput Mater Sci 2007;39(4):782-7. https://doi.org/10.1016/ j.commatsci.2006.09.006.

[15] Ouinas D, BachirBouiadjra B, Serier B. The effects of disbonds on the stress intensity factor of aluminium panels repaired using composite materials. Compos Struct 2007;78(2):278-84. https://doi.org/10.1016/j.compstruct.2005.10.012.

[16] Bouiadjra BB, Ouinas D, Serier B, Benderdouche N. Disbond effects on bonded boron/epoxy composite repair to aluminium plates. Comput Mater Sci 2008;42 (2):220-7. https://doi.org/10.1016/j.commatsci.2007.07.008.

[17] Zarrinzadeh H, Kabir MZ, Deylami A. Crack growth and debonding analysis of an aluminum pipe repaired by composite patch under fatigue loading. Thin-Walled Struct 2017;112:140-8. https://doi.org/10.1016/j.tws.2016.12.023.

[18] Sahli A, Bouziane MM, Benbarek S, Wayne SF, Liang Z, BachirBouiadjra B, Serier B. Experimental and numerical disbond localization analyses of a notched plate repaired with a CFRP patch. Struct Eng Mech 2017; 63(3):361-70. https://doi. org/10.12989/sem.2017.63.3.361

[19] Ban C-S, Lee Y-H, Choi J-H, Kweon J-H. Strength prediction of adhesive joints using the modified damage zone theory. Compos Struct 2008;86(1-3):96-100. https://doi.org/10.1016/i.compstruct.2008.03.016.

[20] Magalhães AG, de Moura MFSF, Gonçalves JPM. Evaluation of stress concentration effects in single-lap bonded joints of laminate composite materials. Int $\mathrm{J}$ Adhes Adhes 2005;25(4):313-9. https://doi.org/10.1016/j. ijadhadh.2004.10.002.

[21] Fari Bouanani M, Benyahia F, Albedah A, Aid A, Bachir Bouiadjra B, Belhouari M, et al. Analysis of the adhesive failure in bonded composite repair of aircraft structures using modified damage zone theory. Mater Des 2013;50:433-9. https:// doi.org/10.1016/i.matdes.2013.03.017.

[22] Ibrahim Chafak N, FariBouanani M, BachirBouiadjra B, Serier B. Analysis of the adhesive damage between composite and metallic adherends: Application to the repair of aircraft structures. Adv Mater Res 2016;5(1):11-20. , https://doi.org/10. 12989/AMR.2016.5.1.011.

[23] Bellali MA, Mokhtari M, Benzaama H, Hamida F, Serier B, Madani K. Using CZM and XFEM to predict the damage to aluminum notched plates reinforced with a composite patch. J Mech Mater Struct 2020;15(2):185-201. https://doi.org/ 10.2140/iomms.2020.15.185.

[24] Khoramishad H, Crocombe AD, Katnam KB, Ashcroft IA. Fatigue damage modelling of adhesively bonded joints under variable amplitude loading using a cohesive zone model. Eng Fract Mech 2011;78(18):3212-25. https://doi.org/ 10.1016/i.engfracmech.2011.09.008.

[25] Da Silva LFM, Campilho RDSG. Advances in numerical modeling of adhesive joints. SpringerBriefs i Appl Sci Technol 2012. https://doi.org/10.1007/978-3642-23608-2.

[26] ABAQUS (2012). ABAQUS User's Manual V 6.12.

[27] Moës N, Dolbow J, Belytschko T. A finite element method for crack growth without remeshing. Int J Numer Methods Eng Wiley 1999;46(1):131-50. https:// doi.org/10.1002/(SICI)1097-0207(19990910)46:13.0.CO;2-J. hal-01004829.

[28] Elruby AY, Nakhla S, Hussein A. Automating XFEM modeling process for optimal failure predictions. Math Prob Eng 2018;2018:1-14. https://doi.org/10.1155 2018/1654751.

[29] Khoramishad H, Crocombe AD, Katnam KB, Ashcroft IA. Predicting fatigue damage in adhesively bonded joints using a cohesive zone model. Int $\mathrm{J}$ Fatigue 2010;32(7):1146-58. https://doi.org/10.1016/j.ijfatigue.2009.12.013.

[30] Hu P, Shi ZW, Wang XX, Li WD, Zhou SG, Han X. Strength degradation of adhesively bonded single-lap joints in a cyclic-temperature environment using a cohesive zone model. J Adhes 2014;91(8):587-603. https://doi.org/10.1080/ 00218464.2014 .915754 .

[31] Benzeggagh ML, Kenane M. Measurement of mixed-mode delamination fracture toughness of unidirectional glass/epoxy composites with mixed-mode bending apparatus. Compos Sci Technol 1996;56(4):439-49. https://doi.org/10.1016/ 0266-3538(96)00005-x.

[32] Madani K, Touzain S, Feaugas X, Cohendouz S, Ratwani M. Experimental and numerical study of repair techniques for panels with geometrical discontinuities. Comput Mater Sci 2010;48(1):83-93. https://doi.org/10.1016/ j.commatsci.2009.12.005.

[33] Autodesk Helius Composite. Helius Composite software bibliographie; 2017.

[34] Santos MAS, Campilho RDSG. Mixed-mode fracture analysis of composite bonded joints considering adhesives of different ductility. Int J Fract 2017;207(1):55-71. https://doi.org/10.1007/s10704-017-0219-x. 